\title{
Tension-type headache and sleep apnea in the general population
}

\author{
Håvard Anton Kristiansen • Kari Jorunn Kværner • \\ Harriet Akre • Britt Øverland • Michael Bjørn Russell
}

Received: 26 August 2010/ Accepted: 25 October 2010/Published online: 16 December 2010

(C) The Author(s) 2010. This article is published with open access at Springerlink.com

\begin{abstract}
The main objective of this study is to investigate the relationship between tension-type headache and obstructive sleep apnea in the general population. The method involves a cross-sectional population-based study. A random age and gender stratified sample of 40,000 persons aged 20-80 years residing in Akershus, Hedmark or Oppland County, Norway were drawn by the National Population Register. A postal questionnaire containing the Berlin Questionnaire was used to classify respondents to be of either high or low risk of obstructive sleep apnea. Included in this study were 297 persons with high risk and 134 persons with low risk of sleep apnea, aged 30-65 years. They underwent an extensive clinical interview, a physical and a neurological examination by physicians, and in-hospital polysomnography. Those with apnea hypopnoea index (AHI) $\geq 5$ were
\end{abstract}

H. A. Kristiansen $(\bowtie)$ - K. J. Kværner · H. Akre ·

B. Øverland · M. B. Russell

Head and neck research group, Research Centre,

Akershus University Hospital, Postbox 65,

1478 Lørenskog, Norway

e-mail: h.a.kristiansen@medisin.uio.no

H. A. Kristiansen · M. B. Russell

Faculty Division Akershus University Hospital,

University of Oslo, Oslo, Norway

\section{K. J. Kværner}

Department of Research and Education,

Oslo University Hospital, Oslo, Norway

\section{K. J. Kværner}

Institute of Health Management and Health Economics,

University of Oslo, Oslo, Norway

H. Akre · B. Øverland

Sleep Unit, Department of Otorhinolaryngology,

Lovisenberg Diakonale Hospital, Oslo, Norway classified with obstructive sleep apnea. Tension-type headache was diagnosed according to the International Classification of Headache Disorders. Results showed the prevalence of frequent and chronic tension-type headache was 18.7 and $2.1 \%$ in the participants with obstructive sleep apnea. The logistic regression analyses showed no significant relationship between tension-type headache and obstructive sleep apnea, with adjusted odds ratios for frequent tension-type headache of $0.95(0.55-1.62)$ and chronic tension-type headache of $1.91(0.37-9.85)$. The results did not change when using cut-off of moderate (AHI $\geq 15$ ) and severe (AHI $\geq 30$ ) obstructive sleep apnea. Thus, we did not find any significant relationship between tension-type headache and the AHI. The presence and severity of sleep apneas seem not to influence presence and attack-frequency of tension-type headache in the general population.

Keywords Tension-type headache $\cdot$ Frequent tension-type headache Chronic tension-type headache Obstructive sleep apnea Polysomnography and epidemiology

\section{Introduction}

Headache and sleep has been linked together for more than a century [1]. Although sleep in migraineurs has been studied repeatedly, less evidence exists regarding the relationship between tension-type headache and sleep [2]. Lack of sleep is frequently reported as precipitating both migraine and tension-type headache [3, 4]. Two previous Danish studies have found sleeping problems to be positively associated with tension-type headache $[5,6]$.

Recently, two new studies have showed a significant relationship between tension-type headache and a range of 
different sleep disturbances measured by validated sleep questionnaires [7,8].

One of the most common sleep disorders is obstructive sleep apnea syndrome, with an estimated prevalence of $2-4 \%$ among middle-aged adults $[9,10]$. Obstructive sleep apnea syndrome is defined as at least five apneas or hypopneas per hour of sleep in conjunction with symptoms such as daytime somnolence. When obstructive sleep apnea is defined solely by an apnea hypopnea index (AHI) of $\geq 5$, the estimated prevalence among middle-aged adults is approximately $20 \%$ in the general population [9, 11, 12]. This is a disorder with partly or complete obstruction of the upper airways during sleep which constitutes hypopnea and apnea and will typically result in repeated airflow cessation, oxygen desaturation and sleep disruption. The disruption of sleep may then result in one or more of the following; excessive daytime sleepiness, unrefreshing sleep, daytime fatigue or reduced cognitive function [13]. Sleep apnea headache is recognized in the International Classification of Headache Disorders (ICHD II) as a brief recurrent morning headache in the presence of an apnea hypopnea index AHI of $\geq 5$ [14]. There is however, still controversy regarding the association between primary headaches and obstructive sleep apnea. The apnea-related headache may present itself as migraine, tension-type, cluster or a non-specific headache, and several studies have found it to merely be a non-specific symptom with no clear relationship with obstructive sleep apnea [15-18].

The aim of the present study was to investigate the relationship between tension-type headache and obstructive sleep apnea in the general population.

\section{Methods}

\section{Sampling and representativeness}

This is a cross-sectional population-based study. An age and gender stratified random sample of 40,000 persons aged 20-80 years old were drawn by the National Population Register. Each of the ages 30, 35, 40, 45, 50, 55 and 60 years included 2,000 persons of each gender, while the remaining ages included 1,000 persons of each gender. The participants were residing in Akershus, Hedmark or Oppland County, Norway. The Counties have both rural and urban areas, and Akershus County is situated in close proximity to Oslo. Data from Statistics Norway has shown that the sampling area were representative for the total Norwegian population regarding age, gender, marital status and level of education [19]. The employment rate was equal, but employment in trade, hotel/restaurant and transport were overrepresented while industry, oil and gas and financial services were underrepresented in the sampling area as compared to the total Norwegian population. As shown in Fig. 1, the sample size was reduced to 38,871 because of error in the address list $(n=1,024)$, multihandicap $(n=4)$, dementia $(n=23)$, insufficient Norwegian language skills $(n=3)$ and deceased $(n=75)$. All participants received a mailed standard letter containing information about the project and a short questionnaire including the Berlin Questionnaire. The Berlin Questionnaire was used to classify respondents to be of either high or low risk of obstructive sleep apnea [20]. This instrument was developed in 1996 and is a ten item self-report questionnaire designed to predict the risk of obstructive sleep apnea. It contains questions in three categories addressing snoring, daytime sleepiness and the presence of hypertension and/or obesity. A positive score in at least two of the three categories are required to classify a person as high risk of obstructive sleep apnea. All others are classified as low risk group of obstructive sleep apnea. Detailed definitions of each category have previously been published [21]. If the questionnaire evoked no response, a second mail was issued. The replies could either be on paper or electronically. The overall response rate was $54.5 \%$ $(21,177 / 38,871)$, and it was significantly higher among women than men ( $n=11,120$ vs. $n=10,057$; $p<0.001$ ). A total of 1,442 questionnaires were not eligible. This was due to late response $(n=41)$, not containing a telephone number necessary for re-contact $(n=729)$ and incomplete filled in questionnaires that could not be classified as high or low risk of obstructive sleep apnea $(n=672)$. An age and gender stratified sample of the respondents aged 30-65 years were then invited by mail to a clinical evaluation and contacted by telephone. The clinical evaluation was conducted over a period of 2 years. If they could not be reached within three attempts, no further attempts were made $(n=202)$. Other exclusion criteria were: Use of Continuous Positive Airway Pressure $(n=10)$, pregnancy $(n=9)$, lack of Norwegian language skills $(n=5)$ and severe physical impairment $(n=4)$. A total of 378 persons with high risk and 157 persons with low risk of sleep apnea were included for further investigations. In case of technical failure in the polysomnography (PSG) recordings, the participants were asked to return for a second recording $(n=6)$. Two persons refrained from such a second PSG recording. Finally, all the participants diagnosed with migraine ( $n=102$ ) were excluded, in order to have a pure material without migraine as a confounder. The final study sample in the present study comprised of 431 (297 high risk and 134 low risk) persons. 585 persons refrained from participating. Participants and non-participants were not significantly different regarding self reported headache, depression, gender or age, while simple snoring was overrepresented in the low risk group, as compared to all low risk respondents of the questionnaire. 
Fig. 1 Flow chart of the study population according to type of participation, $M$ and $F$ denotes males and females

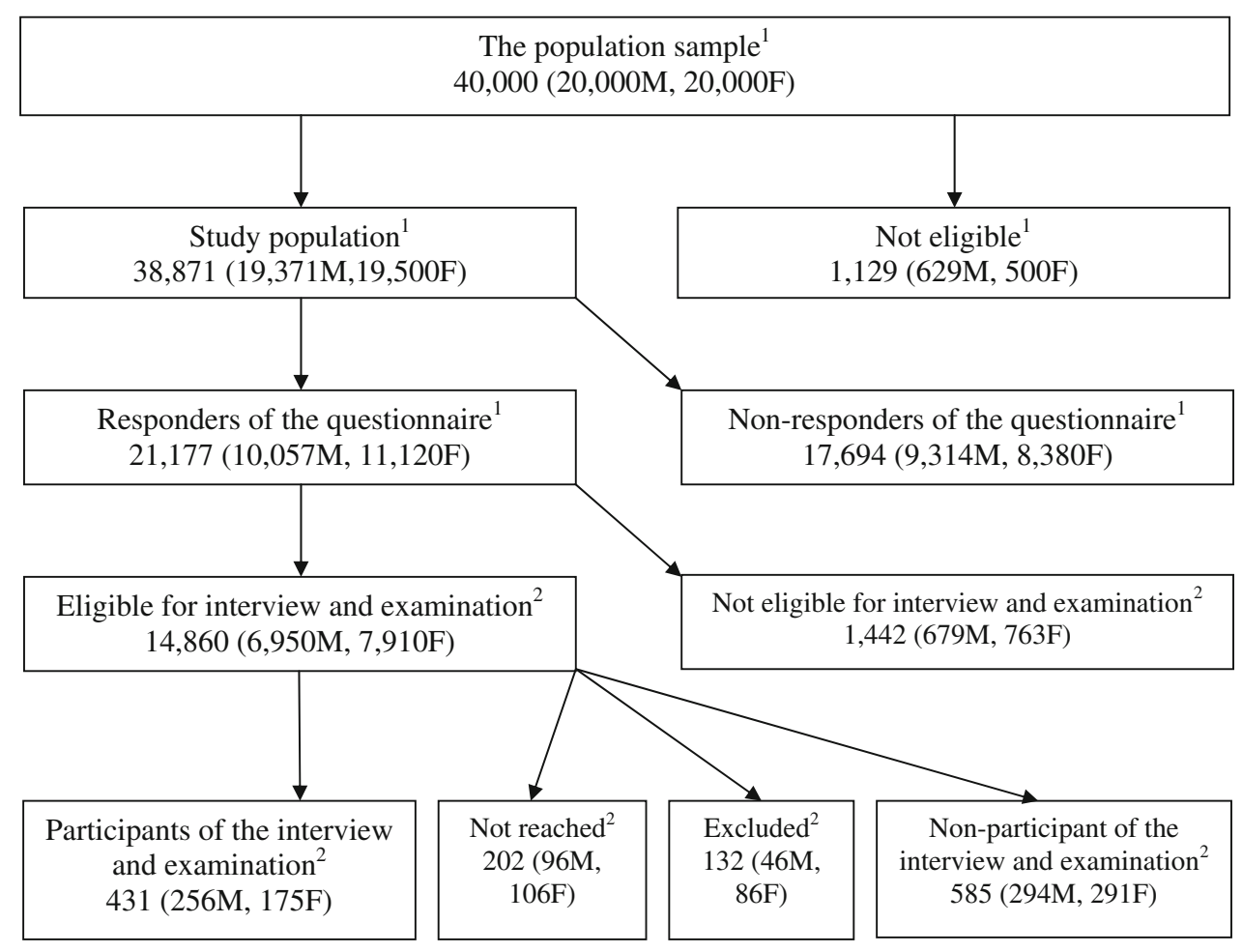

${ }^{1}$ Ages $20-80$ years

${ }^{2}$ Ages $30-65$ years

Clinical evaluation

The participants were all admitted to Akershus University Hospital (Stensby Hospital), Norway and underwent an extensive clinical interview including a semi-structured headache interview and a physical and a neurological examination by one of three physicians. The physicians were blinded regarding the participants replies on the questionnaire. ICHD II was applied [14]. Since the participants with no headache and infrequent tension-type headache did not differ in any of the variables, they were grouped together in the analyses, as $<12$ days of headache per year. The Hospital Anxiety and Depression Scale (HADS) was used to screen for depression [22]. The replies were dichotomized and depression was defined by a score of $\geq 8$ on the subscale of depression (HADS-D) [23]. Excessive daytime sleepiness was assessed by the Epworth Sleepiness Scale [24]. The results were dichotomized into scores $\leq 10$ and $>10$, the latter is considered to represent clinically significant excessive daytime sleepiness [25]. Body mass index $\left(\mathrm{kg} / \mathrm{m}^{2}\right)$ was calculated from measured weight and height. All participants then underwent in-hospital PSG performed on standard, multichannel, Embla $^{\mathrm{TM}}$ A10, PSG devices (ResMed Corp Poway, CA, USA). The recordings included a two-channel electroencephalograph (C4/A1, C3/A2 according to the 10-20 international electrode placement system), a two-channel electrooculogram, a one-channel submental electromyogram, leg EMG (tibialis), $\mathrm{SaO}_{2}$, breathing movements (Respitrace; Ambulatory Monitoring, Ardsley, NY, USA), air flow measured by a nasal air pressure transducer (ProTech, Woodinville, WA, USA) and an oro-nasal thermistor, and body position monitoring. All electrophysiological signals were pre-amplified, stored and subsequently scored (30-s epochs using Somnologica 3.2 software package, Flaga-Medcare, Buffalo, NY, USA) according to the Rechtshaffen and Kales scoring manual by two US board certified PSG technicians who were blinded to the result of the Berlin Questionnaire [26]. Arousals were documented and classified [27]. Obstructive apneas were scored when a $90 \%$ decrease of flow occurred for more than $10 \mathrm{~s}$. Hypopneas were defined as a $30 \%$ decrease in flow for more than $10 \mathrm{~s}$ with subsequent oxygen desaturation of at least $4 \%$. The apnea hypopnoea index (AHI) was calculated as the average of total number of apneas and hypopneas per hour of sleep. In this study, the participants with AHI $\geq 5$ were classified with obstructive sleep apnea.

\section{Statistical analyses}

The statistical analyses were performed using SPSS Base System for Windows 16.0. Power analysis determined that 
a total sample size of 398 participants was required to detect a difference of proportions of headache of $10 \%$, with a power of 80 and a $95 \%$ confidence level. Chi-square tests and logistic regression modelling with 5\% level of significance were used. Fisher's exact test was used when appropriate. The Student's $t$ test and Mann-Whitney $U$ test were used in comparing normally and non-normally distributed continuous variables. In our multivariate logistic regression model obstructive sleep apnea was used as the dependent variable, while tension-type headache, depression, gender, body mass index and age were independent variables.

\section{Ethical issues}

The project was approved by The Regional Committees for Medical Research Ethics and the Norwegian Social Science Data Services.

\section{Results}

In our screening population $23.3 \%(4,942 / 21,177)$ had high risk and $76.7 \%(16,235 / 21,177)$ had low risk for obstructive sleep apnea when using the Berlin Questionnaire as a risk stratifying tool. The distribution of demographic and clinical characteristics of the sample is shown in Table 1. Respondents with high risk of obstructive sleep apnea according to the Berlin Questionnaire were oversampled, resulting in obstructive sleep apnea occurring in 55.9\% (241/431) of the participants. Men had a higher prevalence of obstructive sleep apnea, while women had a higher prevalence of frequent and chronic tension-type headache. The mean body mass index $\left(\mathrm{kg} / \mathrm{m}^{2}\right)$ in the study sample was 28.9 (SD 4.9).

The prevalence of frequent and chronic tension-type headache was $18.7 \%(45 / 241)$ and $2.1 \%(5 / 241)$ in the participants with obstructive sleep apnea, while it was $31.6 \%$ (60/190) and 1.6\% (3/190) in participants with AHI below 5.

When using cutoff of moderate $(\mathrm{AHI} \geq 15)$ and severe (AHI $\geq 30$ ) obstructive sleep apnea, the prevalence of frequent tension-type headache was $14.6 \%$ (20/137) and $14.3 \%$ (10/70), respectively and the prevalence of chronic tension-type headache was $2.2 \%(3 / 137)$ and $0 \%(0 / 70)$, respectively.

The clinical characteristics of tension-type headache were evenly distributed among participants with and without obstructive sleep apnea. The majority in both groups reported bilateral location, pressing/tightening quality, mild/moderate pain intensity, few accompanying symptoms and a duration somewhere between $30 \mathrm{~min}$ up to $24 \mathrm{~h}$.

Table 2 illustrates the polysomnographic characteristics of the sample. As expected in a sample with a high number
Table 1 Demographic and clinical characteristics of the study sample

\begin{tabular}{|c|c|c|c|}
\hline & $\begin{array}{l}\text { Male } \\
n=256 \\
n(\%)\end{array}$ & $\begin{array}{l}\text { Female } \\
n=175 \\
n(\%)\end{array}$ & $\begin{array}{l}\text { All } \\
n=431 \\
n(\%)\end{array}$ \\
\hline \multicolumn{4}{|l|}{ Age $^{\mathrm{a}}$ (years) } \\
\hline 30 and 35 & $53(20.7)$ & $39(22.3)$ & $92(21.4)$ \\
\hline 40 and 45 & $58(22.7)$ & $43(24.6)$ & $101(25.1)$ \\
\hline 50 and 55 & $63(24.6)$ & $47(26.9)$ & $110(25.5)$ \\
\hline 60 and 65 & $82(32.0)$ & $46(26.3)$ & $128(28.0)$ \\
\hline \multicolumn{4}{|l|}{ Depression } \\
\hline Yes & $19(7.5)$ & $17(9.7)$ & $36(8.4)$ \\
\hline No & $234(92.5)$ & $158(90.3)$ & $392(91.6)$ \\
\hline \multicolumn{4}{|l|}{ Body mass index $\left(\mathrm{kg} / \mathrm{m}^{2}\right)$} \\
\hline$<18.5$ & $0(0)$ & $1(0.6)$ & $1(0.2)$ \\
\hline $18.5-24.9$ & $47(18.4)$ & $51(29.1)$ & $98(22.7)$ \\
\hline $25.0-29.9$ & $97(37.9)$ & $64(36.6)$ & $161(37.4)$ \\
\hline$\geq 30.0$ & $112(43.8)$ & $59(33.7)$ & $171(39.7)$ \\
\hline \multicolumn{4}{|c|}{ Excessive daytime sleepiness } \\
\hline Yes & $72(28.2)$ & $54(30.9)$ & $126(29.3)$ \\
\hline No & $183(71.8)$ & $121(69.1)$ & $304(70.7)$ \\
\hline \multicolumn{4}{|c|}{ Obstructive sleep apnea (AHI $\geq 5$ ) } \\
\hline Yes & $168(65.6)$ & $73(41.6)$ & $241(55.9)$ \\
\hline No & $88(34.4)$ & $102(58.3)$ & $190(44.1)$ \\
\hline \multicolumn{4}{|l|}{$\mathrm{AHI} \geq 15$} \\
\hline Yes & $104(40.6)$ & $33(18.9)$ & $137(31.8)$ \\
\hline No & $152(59.4)$ & $142(81.1)$ & $294(68.2)$ \\
\hline \multicolumn{4}{|l|}{$\mathrm{AHI} \geq 30$} \\
\hline Yes & $60(23.4)$ & $10(5.7)$ & $70(16.2)$ \\
\hline No & $196(76.6)$ & $165(94.3)$ & $361(83.8)$ \\
\hline \multicolumn{4}{|l|}{ Tension-type headache } \\
\hline $0-11$ days per year & $210(82.0)$ & $108(61.7)$ & $318(73.8)$ \\
\hline $12-179$ days per year & $43(16.8)$ & $62(35.4)$ & $105(24.4)$ \\
\hline$\geq 180$ days per year & $3(1.2)$ & $5(2.9)$ & $8(1.9)$ \\
\hline
\end{tabular}

${ }^{a}$ Age at sampling of questionnaire data

of participants with obstructive sleep apnea, the amount of minutes with deep sleep (S3 and S4) and REM sleep as well as the mean sleep efficiency were somewhat low. The participants with chronic tension-type headache had a mean sleep efficiency of 88.6 (SD 7.5) and a mean arousal index of 12.7 (SD 6.4) which were not significantly different from participants without chronic tension-type headache. The AHI of the participants with none or infrequent tension-type headache was significantly higher than among those with frequent headache $(p=0.03)$.

Table 3 shows the odds ratios for obstructive sleep apnea by tension-type headache, depression, gender, body mass index and age. The crude probability for frequent tension-type headache was significantly decreased among participants with obstructive sleep apnea. However in the 
Table 2 Polysomnographic characteristics in the participants

\begin{tabular}{|c|c|c|c|c|c|c|}
\hline & \multicolumn{6}{|c|}{ Tension-type headache } \\
\hline & \multicolumn{2}{|c|}{ Less than 12 days per year $(n=318)$} & \multicolumn{2}{|c|}{$12-179$ days per year $(n=105)$} & \multicolumn{2}{|c|}{$\geq 180$ days per year $(n=8$} \\
\hline & Mean & $(\mathrm{SD})$ & Mean & $(\mathrm{SD})$ & Mean & (SD) \\
\hline Total sleep time (min) & 404.3 & 77.5 & 423.3 & 97.1 & 439.8 & 73.9 \\
\hline Sleep efficiency $(\%)$ & 82.8 & 11.0 & 83.8 & 13.5 & 88.6 & 7.5 \\
\hline $\mathrm{S} 1$ of total sleep time $(\%)$ & 7.1 & 6.9 & 5.9 & 6.9 & 4.4 & 2.9 \\
\hline $\mathrm{S} 2$ of total sleep time $(\%)$ & 52.5 & 10.7 & 53.0 & 9.5 & 46.0 & 6.6 \\
\hline $\mathrm{S} 3$ of total sleep time $(\%)$ & 6.9 & 3.6 & 5.9 & 3.2 & 6.9 & 3.1 \\
\hline $\mathrm{S} 4$ of total sleep time $(\%)$ & 16.2 & 7.5 & 16.9 & 7.5 & 20.0 & 4.4 \\
\hline REM of total sleep time (\%) & 17.7 & 6.2 & 18.9 & 6.2 & 22.7 & 5.4 \\
\hline Sleep latency (min) & 38.7 & 73.7 & 44.8 & 89.6 & 79.4 & 86.3 \\
\hline REM latency from sleep onset (min) & 116.4 & 65.6 & 125.8 & 75.0 & 76.8 & 40.6 \\
\hline Arousalindex & 17.9 & 13.4 & 16.1 & 14.0 & 12.7 & 6.4 \\
\hline Apnea hypopnoea index (AHI) & 16.0 & 19.3 & 10.7 & 17.7 & 10.5 & 8.1 \\
\hline Oxygen desaturation index (ODI) & 15.4 & 18.2 & 11.0 & 17.0 & 11.7 & 9.9 \\
\hline Average oxygen saturation $(\%)$ & 94.2 & 1.9 & 94.9 & 1.7 & 94.9 & 0.9 \\
\hline Lowest oxygen saturation (\%) & 84.3 & 6.3 & 85.7 & 7.2 & 85.3 & 4.0 \\
\hline Average desaturation (\%) & 5.4 & 1.6 & 5.1 & 1.4 & 5.1 & 0.9 \\
\hline
\end{tabular}

Table 3 Crude and adjusted odds ratios (cOR and aOR) with 95\% confidence intervals (CI) for obstructive sleep apnea by tension-type headache, depression, gender, body mass index and age

\begin{tabular}{lllll}
\hline & cOR & $95 \%$ CI & aOR & $95 \%$ CI \\
\hline $\begin{array}{l}\text { Tension-type headache } \\
\text { 0-11 days per year }\end{array}$ & Ref & & Ref & \\
12-179 days per year & 0.50 & $(0.32-0.78)$ & 0.95 & $(0.55-1.62)$ \\
$\geq 180$ days per year & 1.11 & $(0.26-4.72)$ & 1.91 & $(0.37-9.85)$ \\
Depression & & & & \\
$\quad$ No & Ref & & Ref & \\
Yes & 0.93 & $(0.53-1.63)$ & 1.12 & $(0.50-2.52)$ \\
Gender & & & & \\
Female & Ref & & Ref & \\
$\quad$ Male & 2.49 & $(1.76-3.54)$ & 2.76 & $(1.75-4.35)$ \\
Body mass index & 1.13 & $(1.08-1.17)$ & 1.15 & $(1.09-1.21)$ \\
Age & 1.07 & $(1.05-1.08)$ & 1.08 & $(1.05-1.10)$ \\
\hline
\end{tabular}

adjusted analysis, the odd ratios for both frequent and chronic tension-type headache showed a non-significant result.

\section{Discussion}

Results

Our main finding was the lack of relationship between tension-type headache and obstructive sleep apnea in the general population. This is in concurrence with a previous clinical population study from Norway [18]. In that study they identified a subgroup of $1.5 \%$ of the patients referred to a neurologist because of headache, to fulfill the criteria of obstructive sleep apnea. This would suggest that obstructive sleep apnea is rather uncommon in patients with difficult headache. The prevalence of tension-type headache was equal in both patients with and without obstructive sleep apnea (7 vs. 9\%) [18]. The consistency of our results is further emphasized by the fact that mild (AHI $\geq 5$ ), moderate $(\mathrm{AHI} \geq 15)$ and severe $(\mathrm{AHI} \geq 30$ ) obstructive sleep apnea 30 showed exactly the same. Such lack of dose-response relationship between headache and severity of obstructive sleep apnea has previously been reported in two case-control studies based on clinic populations from USA and Norway, respectively [16, 28].

There are however, several previous studies indicating a relationship between non-specific headache diagnoses and obstructive sleep apnea [29-31]. These studies often refer to morning headache, chronic daily headache or simply headache. In the present study we have focused strictly on tension-type headache. A recent Norwegian populationbased survey found that severe sleep disturbances were three times more likely in subjects with tension-type headache than in headache free individuals [8]. Sleep disturbances in that survey was based on the Karolinska Sleep Questionnaire with a score in the upper quartile. This questionnaire assesses snoring, apnea, insomnia, daytime sleepiness and restless legs syndrome and in the analysis of the separate items they did not find any differences in the prevalence of snoring or apnea between subjects with tension-type headache and headache free individuals. 
Methodological considerations

The strengths of the present study were the use of interview and examination by physicians regarding the diagnoses of tension-type headache as well as the use of PSG in diagnosing obstructive sleep apnea in participants from the general population. Although the response rate to the questionnaire was relatively low, similar replies to the first and second issued questionnaire as well as the electronic responses, suggest that responders and non-responders are not different. A previous Danish epidemiological survey found no significant difference in the frequency of migraine among responders and non-responders [32]. In addition, the response rate is comparable to that of other sleep-related epidemiologic studies [33, 34].

The relatively low participation rate may introduce a selection bias. However, participants and non-participants were not significantly different regarding self reported headache, depression, gender or age. Regarding the difference between the participants and the study population, we found that self reported simple snoring was somewhat overrepresented in the low risk group in the study sample as compared to the low risk respondents of the questionnaire. If there is a relationship between snoring and headache, this may have introduced a misclassification bias resulting in a slight overestimation of headache in participants without obstructive sleep apnea in our study [29, 35]. This will not, however, influence our finding that tension-type headache and the AHI was not significantly related. As with most studies, a larger sample may have demonstrated greater precision of the results. Since this was an epidemiologic study of the general population, the amount of participants with chronic tension-type headache was small. This requires a more cautious interpretation of the statistical findings regarding chronic tension-type headache, since we cannot exclude a type- 2 error due to the small numbers. Finally, it cannot be completely ruled out that the use of single in-patient PSG may be a potential limitation to our study [36]. Although the mean total sleep time in this sample was 409.6 min, which may represent a first night effect, we believe the latter is more important in measuring of the sleep quality than in diagnosing of obstructive sleep apnea.

\section{Conclusion}

The presence and severity of sleep apneas seem not to influence presence and attack-frequency of tension-type headache in the general population.

Acknowledgments This study was supported by a grant from South-East Norway Regional Health Authority, grant number
2004219. The Faculty Division Akershus University Hospital kindly provided technical support. Thanks to Akershus University Hospital for providing research facilities.

Conflict of interest None of the authors have any financial or other relationships that might lead to a conflict of interest.

Open Access This article is distributed under the terms of the Creative Commons Attribution Noncommercial License which permits any noncommercial use, distribution, and reproduction in any medium, provided the original author(s) and source are credited.

\section{References}

1. Dodick DW, Eross EJ, Parish JM, Silber M (2003) Clinical, anatomical, and physiologic relationship between sleep and headache. Headache 43:282-292

2. Rains JC, Poceta JS, Penzien DB (2008) Sleep and headaches. Curr Neurol Neurosci Rep 8:167-175

3. Drake ME Jr, Pakalnis A, Andrews JM, Bogner JE (1990) Nocturnal sleep recording with cassette EEG in chronic headaches. Headache 30:600-603

4. Spierings EL, Ranke AH, Honkoop PC (2001) Precipitating and aggravating factors of migraine versus tension-type headache. Headache 41:554-558

5. Langemark M, Olesen J, Poulsen DL, Bech P (1988) Clinical characterization of patients with chronic tension headache. Headache 28:590-596

6. Rasmussen BK (1993) Migraine and tension-type headache in a general population: precipitating factors, female hormones, sleep pattern and relation to lifestyle. Pain 53:65-72

7. Yeung WF, Chung KF, Wong CY (2010) Relationship between insomnia and headache in community-based middle-aged Hong Kong Chinese women. J Headache Pain 11:187-195

8. Odegard SS, Engstrom M, Sand T, Stovner LJ, Zwart JA, Hagen K (2010) Associations between sleep disturbance and primary headaches: the third Nord-Trondelag Health Study. J Headache Pain 11:197-206

9. Young T, Palta M, Dempsey J, Skatrud J, Weber S, Badr S (1993) The occurrence of sleep-disordered breathing among middle-aged adults. N Engl J Med 328:1230-1235

10. Kripke DF, Ancoli-Israel S, Klauber MR, Wingard DL, Mason WJ, Mullaney DJ (1997) Prevalence of sleep-disordered breathing in ages 40-64 years: a population-based survey. Sleep 20:65-76

11. Duran J, Esnaola S, Rubio R, Iztueta A (2001) Obstructive sleep apnea-hypopnea and related clinical features in a populationbased sample of subjects aged 30-70 years. Am J Respir Crit Care Med 163:685-689

12. Bixler EO, Vgontzas AN, Lin HM, Ten HT, Rein J, Vela-Bueno A et al (2001) Prevalence of sleep-disordered breathing in women: effects of gender. Am J Respir Crit Care Med 163:608-613

13. The Report of an American Academy of Sleep Medicine Task Force (1999) Sleep-related breathing disorders in adults: recommendations for syndrome definition and measurement techniques in clinical research. Sleep 22:667-689

14. Headache Classification Subcommittee of the International Headache Society (2004) The International Classification of Headache Disorders, 2nd edn. Cephalalgia 24 Suppl 1:9-160

15. Alberti A, Mazzotta G, Gallinella E, Sarchielli P (2005) Headache characteristics in obstructive sleep apnea syndrome and insomnia. Acta Neurol Scand 111:309-316 
16. Aldrich MS, Chauncey JB (1990) Are morning headaches part of obstructive sleep apnea syndrome? Arch Intern Med 150:1265-1267

17. Poceta JS, Dalessio DJ (1995) Identification and treatment of sleep apnea in patients with chronic headache. Headache 35:586-589

18. Jensen R, Olsborg C, Salvesen R, Torbergsen T, Bekkelund SI (2004) Is obstructive sleep apnea syndrome associated with headache? Acta Neurol Scand 109:180-184

19. Russell MB, Kristiansen HA, Saltyte-Benth J, Kvaerner KJ (2008) A cross-sectional population-based survey of migraine and headache in 21, 177 Norwegians: the Akershus sleep apnea project. J Headache Pain 9:339-347

20. Netzer NC, Stoohs RA, Netzer CM, Clark K, Strohl KP (1999) Using the Berlin Questionnaire to identify patients at risk for the sleep apnea syndrome. Ann Intern Med 131:485-491

21. Chung F, Yegneswaran B, Liao P, Chung SA, Vairavanathan S, Islam S et al (2008) Validation of the Berlin Questionnaire and American Society of Anesthesiologists checklist as screening tools for obstructive sleep apnea in surgical patients. Anesthesiology 108:822-830

22. Zigmond AS, Snaith RP (1983) The hospital anxiety and depression scale. Acta Psychiatr Scand 67:361-370

23. Bjelland I, Dahl AA, Haug TT, Neckelmann D (2002) The validity of the Hospital Anxiety and Depression Scale. An updated literature review. J Psychosom Res 52:69-77

24. Johns MW (1991) A new method for measuring daytime sleepiness: the Epworth sleepiness scale. Sleep 14:540-545

25. Johns MW (1994) Sleepiness in different situations measured by the Epworth Sleepiness Scale. Sleep 17:703-710

26. Rechtschaffen A, Kales A (1968) A manual of standardized terminology, techniques and scoring system for sleep stages of human subjects. Los Angeles, University of California, Brain Information Service/Brain Research Institute

27. Bonnet M, Carley D, Carskadon M, Easton P, Guilleminault C, Harper R et al (1992) EEG arousals: scoring rules and examples: a preliminary report from the Sleep Disorders Atlas Task Force of the American Sleep Disorders Association. Sleep 15:173-184

28. Sand T, Hagen K, Schrader H (2003) Sleep apnoea and chronic headache. Cephalalgia 23:90-95

29. Ulfberg J, Carter N, Talback M, Edling C (1996) Headache, snoring and sleep apnoea. J Neurol 243:621-625

30. Boutros NN (1989) Headache in sleep apnea. Tex Med 85:34-35

31. Provini F, Vetrugno R, Lugaresi E, Montagna P (2006) Sleeprelated breathing disorders and headache. Neurol Sci 27(Suppl 2):S149-S152

32. Russell MB, Rasmussen BK, Thorvaldsen P, Olesen J (1995) Prevalence and sex-ratio of the subtypes of migraine. Int J Epidemiol 24:612-618

33. Ancoli-Israel S, Roth T (1999) Characteristics of insomnia in the United States: results of the 1991 National Sleep Foundation Survey. I. Sleep 22(Suppl 2):S347-S353

34. Pallesen S, Nordhus IH, Omvik S, Sivertsen B, Tell GS, Bjorvatn B (2007) Prevalence and risk factors of subjective sleepiness in the general adult population. Sleep 30:619-624

35. Jennum P, Hein HO, Suadicani P, Gyntelberg F (1994) Headache and cognitive dysfunctions in snorers. A cross-sectional study of 3323 men aged 54-74 years: the Copenhagen Male Study. Arch Neurol 51:937-942

36. Stepnowsky CJ Jr, Orr WC, Davidson TM (2004) Nightly variability of sleep-disordered breathing measured over 3 nights. Otolaryngol Head Neck Surg 131:837-843 